\title{
Aprovechamientos de los recursos naturales del Parque Natural Sierra Norte
}

Rafael Pérez de Guzmán Puya

Licenciado en Biología

\section{Resumen}

Los usos y aprovechamientos de lo que es hoy el Parque Natural Sierra Norte, han ido modificándose según las necesidades de las personas que lo han habitado y habitan. Así vemos que actividades como la dehesa, plantas medicinales, destilerías, minería y otras, han ido perdiendo protagonismo, algunas hasta desaparecer, en pro de otro tipo de actividades como el turismo rural y de naturaleza, caza, pesca, gastronomía, corcho, etc.

\section{Palabras clave}

Parque Natural Sierra Norte / Ganadería extensiva / Emigración / Minería / Montanera / Descorche / Desarrollo sostenible

El pilar básico de la economía serrana es el sector primario, encabezado por la ganadería y seguido por una agricultura orientada en gran medida a la alimentación del ganado, encontrando que industria y servicios están por debajo de la media provincial.

La pérdida de valor económico del uso que se hacía de las dehesas ha resultado ser el principal problema para el medio ambiente, debido a que se permite el avance del matorral o el envejecimiento de encinas y alcornoques, con lo que pierde calidad su amplio muestrario de efectos beneficiosos. Y, por supuesto, esta situación repercute una bajada en la calidad de vida en los pobladores de la sierra, como demostró la tremenda emigración de los años 60.

La garantía de ingresos que supone la dehesa está en crisis, y el resto de aprovechamientos posibles en la comarca no se han desarrollado o incluso han desaparecido, como es el caso de la vid, antaño el comercio más floreciente, o el lino. Por otro lado, el olivar ha experimentado cierto crecimiento, pero con una explotación de baja intensidad obligada por la escasa calidad del suelo.

Mejor fruto tiene el alcornocal, siempre que el cultivo se complemente con la industria transformadora adecuada. Lo mismo que ocurre con los famosos aguardiente de Cazalla y Constantina, en paulatina pérdida de pujanza que, no obstante, puede cambiar de signo tras una reciente entrada de capital foráneo.
La riqueza natural de la Sierra Norte está todavía a la espera de que se rentabilice. Todos los expertos coinciden en la potencialidad de las setas, plantas aromáticas y medicinales, y por supuesto de la caza y pesca, sin olvidar el factor de calidad que se puede añadir para valorar mejor los típicos productos serranos, como sus cerdos o la leche.

Los aprovechamientos de esta tierra han encontrado un filón en el turismo gastronómico y de naturaleza, el sector económico de más empuje en nuestra sociedad del ocio. Pero aquí se manifiestan algunas carencias, cada día afortunadamente menores gracias a iniciativas privadas y públicas que ofertan los encantos del Parque Natural a un visitante de calidad.

La prestación de servicios turísticos parece uno de los futuros más nítidos para los pobladores del Parque Natural como renta complementaria. Lejos quedan los tiempos en que las minas fueron un bastión de riqueza, e incluso fama, fuera de sus fronteras. La Mina Rica de Guadalcanal, agotada tras dos siglos, el Cerro del Hierro... explotaciones que hasta dieron origen a los primeros altos hornos de España, la Fábrica de El Pedroso.

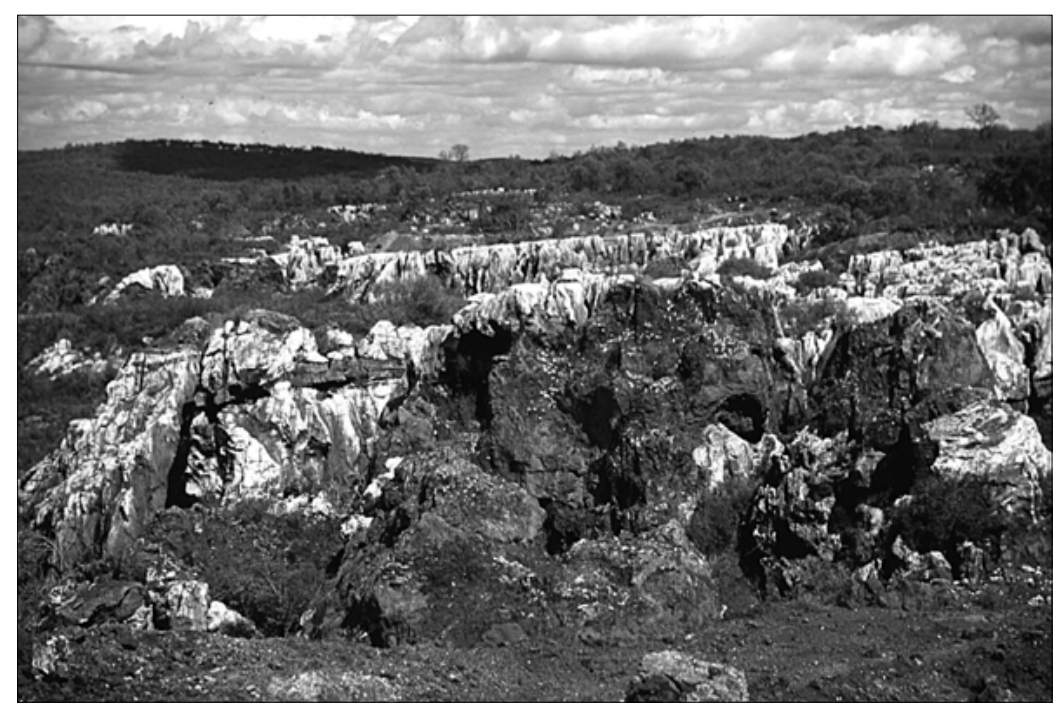

Pero en esta comarca de delicado equilibrio entre el medio y la economía -interdependientes- no se ha perdido del todo casi ninguno de los aprovechamientos naturales. La madera, el corcho, la recogida de frutos y setas. Y por supuesto dos de sus más boyantes prácticas: la caza, que encuentra en Sierra Norte el enclave imprescindible para su práctica, y la explotación de la dehesa, la antiquísima gran madre de la riqueza medioambiental del Parque Natural. 

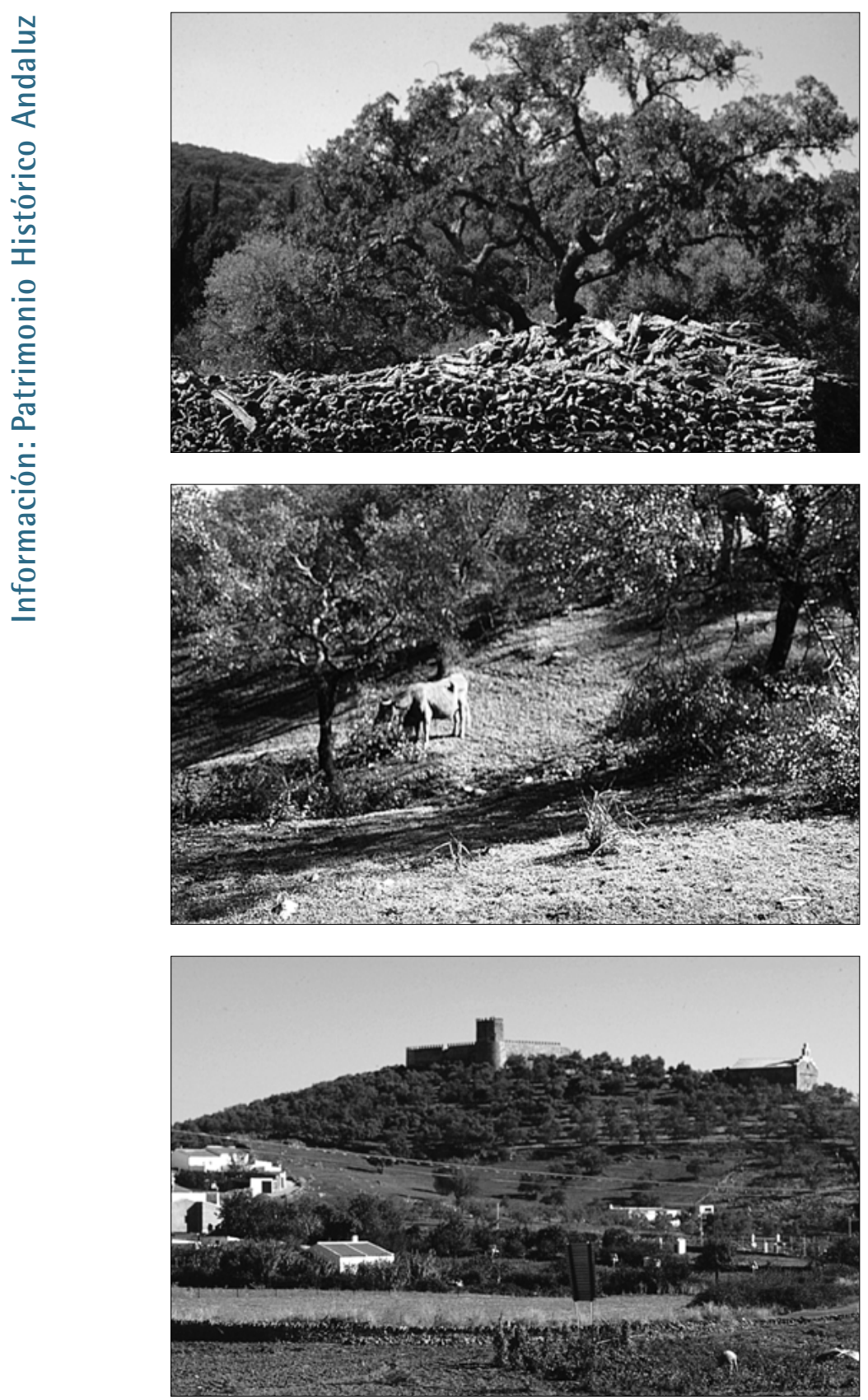

Aprovechamiento del corcho

Poda encinar y su aprovechamiento para "ramoneo" del ganado

Aprovechamiento del olivar

\section{Aprovechamientos forestales. Madera, leña, corcho, varas de castaño}

El principal aprovechamiento forestal de la dehesa es el corcho, el caparazón epidérmico en que se envuelve el alcornoque para protegerse del fuego y de las oscilaciones de temperatura. Son células vegetales muertas que se llenan de aire, formando un material que la tecnología no ha encontrado sustituto. Desde los tiempos de los romanos se utiliza en la elaboración de calzado, y por supuesto para tapar recipientes que contengan líquido.

Es difícil calcular cuanto alcornocal hay en el Parque Natural, pues se encuentra muy mezclado con encinas. Las masas puras de alcornoques se estiman en 4.500 hectáreas, mientras que hay 33.600 hectáreas de bosque con ambas quecíneas.
La extracción del corcho es una maniobra que nos devuelve a tiempos pasados, ya que se sigue haciendo como siempre: a mano y con cuidadosos golpes de hacha para no dañar al árbol. La primera saca del corcho se llama desbornizamiento, y a partir de entonces se repite cada nueve años.

El corcho se lleva a la industria transformadora, que ha venido menguando en la comarca. Sin embargo, hoy día recupera brío.

La extracción de madera se concentra casi exclusivamente en pinos y eucaliptos, especies introducidas en la Sierra Norte con ese fin. De los primeros hay unas 900 hectáreas, y de eucaliptos, I.700, y en descenso por su nefasto impacto sobre el resto de la vida animal y vegetal. Son árboles de rápido crecimiento, mucho mayor que el de las especies autóctonas. De ahí que el uso maderero de castaños o chopos sea prácticamente testimonial. De los castaños sí se continúan aprovechando sus varas, con las que varear los olivos para hacer caer sus frutos, y también para la fabricación de vigas, duelas y tutores para los árboles.

También ha desaparecido prácticamente la fabricación de carbón vegetal a partir de leña obtenida de las podas, el carboneo para el que se construían unas características estructuras circulares de madera (boliches).

Pero si se sigue fabricando el picón o cisco para los braseros, con los que calentarse en la camilla con un toque de alhucema para dar buen olor. Se hace echando pequeñas ramas en el boliche, de forma que en unas horas ya están convertidas en el carboncillo apropiado.

\section{Olivas y aceite}

El olivar es parte intrínseca de la cultura mediterránea. En el Parque Natural ha ido extendiendo sus dominios hasta las 16.000 hectáreas actuales; de pequeñas manchas a grandes paisajes que se pueden contemplar sobre todo en Constantina, Cazalla y Guadalcanal. El olivar se asienta en suelos calizos, terrenos marginales de tanta pendiente que a veces dificulta su recogida.

El olivo (Olea europaea) es una variante del acebuche (variedad sylvestris) del que se aprovecha la leña, pero sobre todo su fruto, que ha servido para medicinas, cosméticos, y sobre todo para su moltura y conversión en aceite, uso actual junto a una pequeña producción de aceituna de mesa.

La antigüedad de las plantaciones de olivos en el Parque Natural motiva que la variedad de frutos sea grande. Picual, pico-limón, martero, zorzaleño, manzanilla... producen un aceite cada vez más valorado. La prueba es que son tres las marcas autóctonas que salen al mercado: La Naverita, que engloba la producción de Las Navas, Sierra Norte, abastecida por doce cooperativas de toda la comarca, y Sierra de Guadalcanal, envasado en la localidad. 
Los molinos a la antigua usanza ya casi han desaparecido. Su uso está limitado a El Pedroso, con el molturado a base de rulos de piedra, y las prensas de donde salía el aceite.

El olivar serrano tiene ejemplares de hasta 500 años. Está envejecido por falta de podas y tiene una baja producción (de 500 a 1.000 kilos por hectárea), siendo frecuente que la cosecha sólo se efectúe en los años buenos. Incluso las grandes propiedades explotan como dehesa con pastizales, con un aprovechamiento ganadero.

El aceite de la Sierra Norte tiene buenas propiedades organolépticas (sabor y olor). En los últimos años se están haciendo esfuerzos en ir mejorando la calidad, cuidándose todo el proceso de producción.

\section{La ganadería y sus productos}

Pastos, bellotas y matorral son el sustento de la cabaña ganadera del Parque Natural criada de forma extensiva, estimada en unas 180.000 cabezas, repartidas entre ganado ovino, porcino, caprino y vacuno.

Aunque se ha propagado el engorde con pienso y la producción intensiva e incluso industrial (aves), persiste el sistema tradicional extensivo, aprovechando pastos y frutos (sobre todo bellota). Esto es así desde el origen de los primeros asentimientos humanos, y se afianzó con los privilegios reales a la organización de ganaderos del Medievo, la Mesta.

La raza vacuna dominante es la retinta, las de raza pura se suelen cruzar con toros de raza charolesa o, sobre todo, limosina; para su comercialización a través de la venta del ternero al destete -con unos 200 kilos-. De la raza frisona se obtiene la leche (en especial en Cazalla, Constantina, La Puebla y Guadalcanal), que es vendida a grandes centrales lecheras o, también, fresca para el mercado local. Por supuesto, se pueden encontrar quesos de la tierra, tanto de vaca como de cabra.

La lana de las ovejas merinas dejó de ser, en el siglo XIX, el producto estrella de la utilización de las dehesas. El ganado ovino se comercializa hoy día por su carne.

El ganado caprino es el único capaz de sacar provecho del matorral. La raza predominante es la serrana, muy bien adaptada a lo que puede comer aquí, pero de poco rendimiento lechero. Así que su aprovechamiento primordial también es el cárnico, origen de algunos típicos platos, aunque asimismo sirve para hacer quesos. Si antes su producción era casera y para su consumo familiar, ya puede el viajero encontrarlos comercializados.

Los cerdos son fundamentales en la pervivencia de la dehesa, dando rentabilidad a este tipo de explotación y, por tanto, garantizando la existencia del ecosistema. El cerdo alimentado principalmente con be-
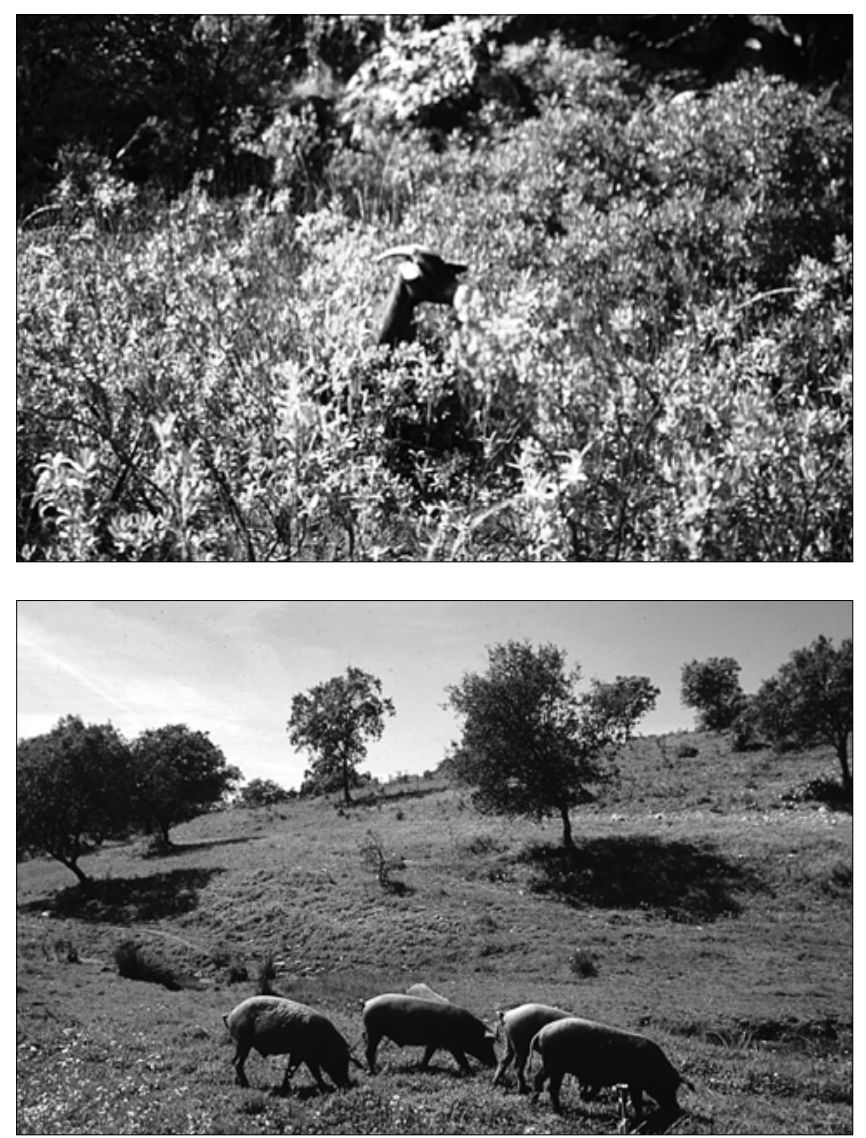

llotas, ha descendido por las prácticas industriales. Pero aún es un espectáculo habitual la montanera, el periodo de otoño y principios de invierno en que se cae la bellota y estos omnívoros la devoran al pie de la encina. La industria del cerdo no está del todo desarrollada en la comarca, aunque en la actualidad está en expansión.

\section{Caza y pesca}

En el Libro de la Montería del monarca castellano Alfonso XI (siglo XIV) se relataba la abundancia de osos, puercos y venados en las sierras de la comarca. En 1730 el príncipe el príncipe de Asturias, don Fernando, tiró codornices durante dos meses en Cazalla. La Cartuja de esta localidad se dice que también fue usada como pabellón de caza por Pedro I el Cruel.

Egregios ejemplos de una actividad cinegética que sigue siendo de primer orden en la Sierra Norte, incluso más ahora al convertirse en cotos dehesas que antes tenían un uso agropastoral. Las principales especies son el ciervo, jabalí, conejo, liebre, paloma torcaz, paloma bravía, tórtola común, perdiz roja, codorniz, zorzal común, zorzal alirrojo y estornino negro.

La caza mayor se sustenta en jabalí y ciervo (o venado), aunque hay pequeñas poblaciones de muflones y gamos. El jabalí abunda en Cazalla y El Pedroso, vivaqueando en las dehesas de bosque mediterráneo
Aprovechamiento del monte con ganado caprino

Aprovechamiento de la dehesa 

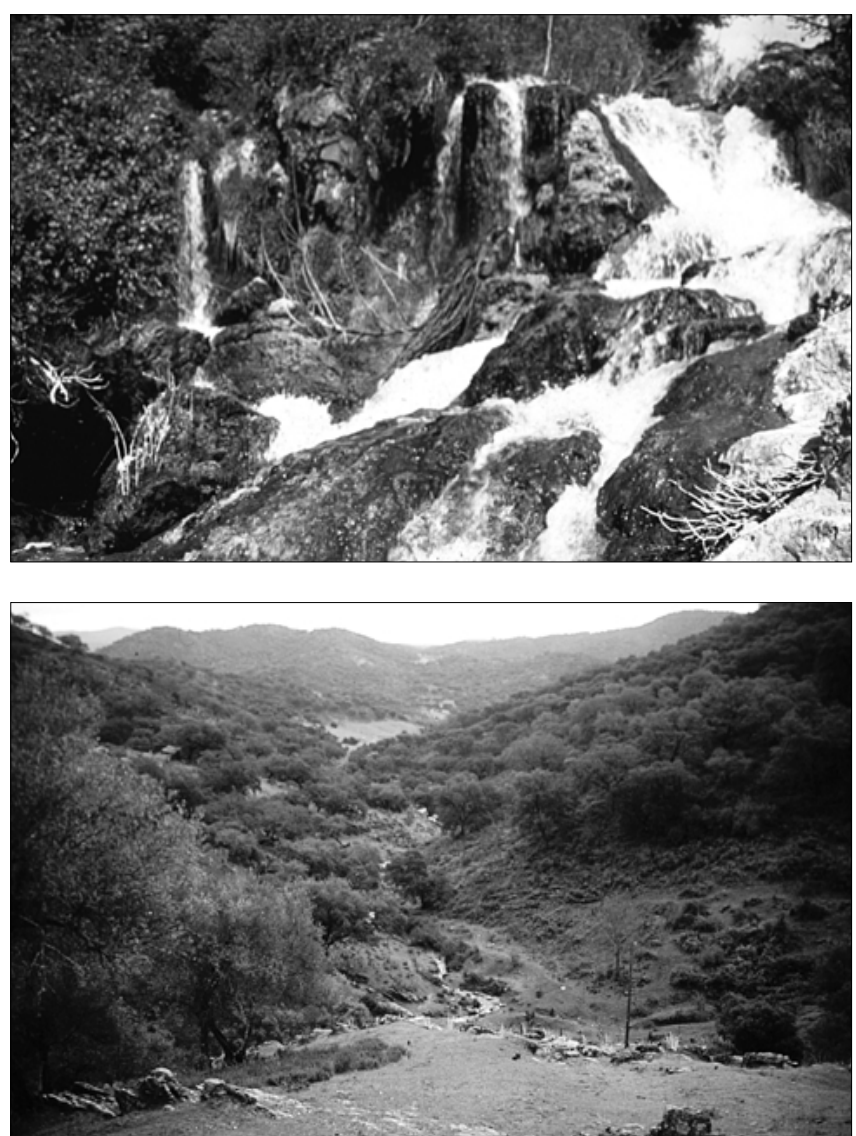

Rivera del Huesna

durante las horas de poca luz, para esconderse en el monte más espeso durante el día. Un hábitat más aclarado busca el ciervo, para encontrar el pasto del que se alimenta. Abunda en Alanís y El Pedroso.

La caza menor sí ha sufrido cierta regresión de especímenes. Sus principales exponentes son la perdiz (que abunda en Guadalcanal y Constantina), el conejo y la liebre. Después las aves migratorias: palomas y zorzales.

La mayoría de la producción de carne está destinada al autoconsumo, ya sea de cazadores nativos o por parte de los titulares de los cotos no residentes (unos 8.000 por temporada, más otros tantos acompañantes), como los que acuden a jornadas comercializadas (unos 500).

El periodo de caza se desarrolla normalmente en otoño e invierno, siempre supeditado a los periodos establecidos por la Consejería de Medio Ambiente, aunque en verano es cuando se tira a las palomas y se abre la media veda para aves.

La pesca es otra actividad que encuentra en la Sierra Norte exponentes únicos, como es la captura de la trucha en la rivera del Huesna. A la calidad y cantidad de los recursos se une el poder practicar este deporte en los hermosos parajes que crea el bosque de galería.

Aficionados de todas las provincias limítrofes se acercan al Huesna para probar suerte con la trucha común o la arco iris. La práctica de la pesca se encuentra regulada en tres cotos: Coto Rivera del Huesna (sin muerte), Coto Rivera del Huesna (con muerte) y Coto intensivo Molino del Corcho.

Destaca la abundancia de ciprínidos en los embalses, particularmente apreciadas son las carpas del Pintado, así como la presencia de bogas, barbos y black bass en numerosas láminas de agua (embalses del Retortillo y Huesna).

\section{Apicultura}

La miel es uno de los productos más tradicionales y exquisitos de la Sierra Norte. Aún son muchísimos los habitantes que el cuidado de algunas colmenas, tanto como costumbre heredada de sus mayores como para el consumo doméstico del producto.

La miel típica de la comarca es la denominada milflores o de monte, realizada con la libación que hacen las abejas de la extraordinaria variedad de flores (lavanda, tomillo, jara, romero...) que se abren en el campo cuando llega la primavera. Es un producto artesanal, no comercializado bajo ninguna marca.

La colmena tradicional es la de corcho, que acostumbraba a verse en cualquier cortijo o casa de campo. La colmena actual, técnicamente, está muy perfeccionada, teniendo por separado la zona donde se va depositando la miel y la que requieren estos insectos para la cría, de manera que la producción es mayor, un promedio de 40 kilos por colmena, aunque dependerá mucho de la climatología.

La apicultura significa en la sierra unos ingresos económicos complementarios, nunca el medio de vida exclusivo. Cuando llega la época algunas empresas colmeneras colocan colmenas en algunos puntos seleccionados, pagando alguna cantidad al dueño del terreno.

Además de plantas silvestres se aprovecha el naranjo, y al llegar el verano se trasladan las colmenas a los campos de girasol, produciéndose así miel de una sola flor, muy apreciada hoy día por los consumidores.

La apicultura no sólo tiene la potencialidad de convertirse en unos ingresos importantes para la Sierra Norte, cuando el producto se transforma in situ, sino que tiene un gran valor ecológico, por la polinización que hacen las abejas de las plantas, clave par su reproducción y la diversidad genética.

\section{Setas}

La Sierra Norte tiene una gran potencialidad, siendo su flora fúngina muy variada, uno de los secretos que esconde todavía el Parque Natural. Se recogen en otoño, aunque algunas que se pueden encontrar en cualquier época, exceptuando el verano. 
Las más abundantes y usadas son las setas de álamo o chopo (género Pholiota). No son las más sabrosas, pero sí las menos peligrosas al no incluir especies venenosas.

También se aprecia mucho el faisán (Boletus edulis), - las llamadas setas de cardo (género Plerotus), así como el níscalo (Lactarius deliciosus), que se cría en los pinares, y la Amanita cesárea, un manjar de dioses que comparte género con la faloides y muscaria, dos especies muy venenosas.

\section{Plantas aromáticas y medicinales}

La riqueza del monte mediterráneo que predomina en el Parque Natural tiene su mejor muestra en el aprovechamiento obtenido de sus especies vegetales para uso alimentario, medicinal o cosmético. Esto lo supieron los primeros hombres que pusieron pie en la Sierra Norte, y ahora está convertido en una industria cuyos productos son apreciadísimos en los mercados europeos.

La extensa superficie forestal del Parque Natural es propia para el crecimiento silvestre de plantas cuyas flores, hojas o incluso tallos tienen propiedades nutritivas, odoríferas o sanadoras. La más importante en cuanto a nivel de recolección es la jara, al contener un aceite esencial apreciado en perfumería por su aroma a incienso y cuero. Se recolecta en verano, al igual que el tomillo, que florece hacia junio o julio y, además de su uso como condimento alimenticio, también es apreciado por la industria farmacéutica por el cistral que contiene, el cual ofrece resultados antisépticos.
El orégano es abundante y muy utilizado en la cocina; como el romero, que se recolecta del campo en marzo o abril, y extiende sus virtudes más allá de los fogones, ya que el olor de su esencia es componente de perfumes, e incluso es bueno para el hígado y los problemas respiratorios, como conoce el saber popular.

El olor de la flor de la siempreviva (llamada en la comarca manzanilla), o las propiedades del poleo provocan que estas dos especies también tengan un aprovechamiento en la Sierra Norte.

La calidad de los productos logrados es fácil de explicar, a las condiciones naturales del clima se une el carácter silvestre de las plantas, no tratadas nunca químicamente, cuya recolección se hace a mano y con una hoz, cuidando de que la raíz no resulte dañada para asegurar la supervivencia de la mata. Una vez lograda la materia prima, el sistema más utilizado para transformar en un producto comerciable es la destilación.

Del fruto del lentisco se obtenía aceite para alumbrar. Del enebro también se podía obtener, como antaño, aceite de propiedades desinfectantes.

Entre las especies de más apreciado uso alimenticio hay que destacar, sin duda, al palmito y el espárrago. A pesar del valor culinario de estas dos plantas, no hay una dedicación industrial o comercial en la comarca. Tanto las yemas que en primavera salen de la esparraguera, como la parte subterránea y comestible del tronco de la peculiar palmera enana que es el palmito, se han recogido tradicionalmente en el lugar para ofrecerlas en tiendas, carreteras o mercados locales.

\section{Bibliografía}

Plan de Ordenación de Recursos Naturales y Plan Rector de Uso y Gestión del Parque Natural Sierra Norte. Consejería de Medio Ambiente. 1994

Supervivencia de la Sierra Norte de Sevilla. Casa Velázquez. 1992.

Avance de planificación en el Parque Natural de Sierra Norte. Agencia de Medio Ambiente. 1991.

Plan Forestal Andaluz. La Dehesa. Consejería de Agricultura y Pesca. 1992.
Estudio de la flora amenazada y formaciones vegetales de interés del Parque Natural Sierra Norte. Consejería de Medio Ambiente. 1997.

Permanencia y cambio en la Sierra Norte de Sevilla. María Dolores Requena Sánchez. Grupo de Investigación Estudios Integrados de Geografía.

Mapa de cultivos y aprovechamientos. Ministerio de Agricultura, Pesca y Alimentación.

Acercamiento a la rivera del Huesna. Manuel Rodríguez de la Rosa. Editorial Guadalmena. 